\title{
Impedance spectroscopy, electrical relaxation and Ac conductivity studies of organic-inorganic hybrid compound: $\mathrm{NH}_{3}\left(\mathrm{C}_{6} \mathrm{H}_{4}\right)_{2} \mathrm{NH}_{3} \mathrm{HgCl}_{4}$
}

\author{
W. Wamani*, N. Hannachi, T. Mhiri and M. Belhouchet \\ Laboratoire Physico-Chimie de l'Etat Solide, Université de Sfax, Département de Chimie, Faculté des \\ Sciences de Sfax, B. P. 1171, 3000 Sfax, Tunisia. \\ Laboratoire de l'Etat Solide, Université de Sfax, Département de physique, Faculté des sciences de Sfax, \\ B.P.1171, 3000 Sfax, Tunisia \\ *Corresponding author: wafawamani@yahoo.fr

\begin{abstract}
Organic-inorganic hybrid sample $\mathrm{NH}_{3}\left(\mathrm{C}_{6} \mathrm{H}_{4}\right)_{2} \mathrm{NH}_{3} \mathrm{HgCl}_{4}$ was characterized by differential scanning calorimetry (DSC), TGA analysis and electrical impedance spectroscopy. DSC studies indicated the presence of a one-phase transition at $391 \mathrm{~K}$. As for the ac conductivity of the compound $\mathrm{NH}_{3}\left(\mathrm{C}_{6} \mathrm{H}_{4}\right)_{2} \mathrm{NH}_{3} \mathrm{HgCl}_{4}$, it has been measured in the temperature range of 358 $413 \mathrm{~K}$ and the frequency range of $209 \mathrm{~Hz}-5 \mathrm{MHz}$. Concerning the Z' and Z" versus frequency plots, they were well-fitted to an equivalent circuit model. The equivalent circuit is composed of a series of combination of two parallel (R//CPE) circuits. Besides, the frequency dependence of the conductivity was interpreted in terms of Jonscher's law $\sigma(\omega)=\sigma_{d c}+A \omega^{n}$. As regards the conductivity, it follows the Arrhenius relation. The variation of the value of the conductivity with temperatures confirmed the availability of the phase transition at $391 \mathrm{~K}$ detected by DSC and electrical measurements.
\end{abstract}

Keywords: Organic-inorganic hybrid; Thermal behaviour; Electrical impedance spectroscopy; Equivalent circuit; AC conductivity.

\section{Council for Innovative Research}

Peer Review Research Publishing System

\section{Journal: Journal of Advances in Chemistry}

Vol. 7, No. 2

editor@cirworld.com

www.cirworld.com, member.cirworld.com 


\section{INTRODUCTION}

The hybrid organic-inorganic materials have generated a lot of interest from the technological and scientific points of view [1, 2]. The tetrachloromercurate of 1,4-biphenylenediaminuim has been synthesized as part of a major research area in order to study the remarkable properties of organic-inorganic hybrids. These compounds offer, scientifically and technologically significant opportunities in different areas of catalysis, optical properties, biology, magnetic functional materials, and electronics [3-11]. For the most part, organic amines were used as the organic component and divalent metal chlorides as the inorganic one [12]. In fact, organic molecules have specific properties of high fluorescence efficiency, large polarizability, plastic mechanical properties and structural diversity. Besides, inorganic materials may be characterized by a wide range of electronic properties, magnetic and dielectric transitions, substantial mechanical hardness and thermal stability [13]. Furthermore, optical, electrical, magnetic, and thermodynamic properties are useful in many applications and have attracted great attention [13]. Significant effort has been placed on both experimental and theoretical studies in this family of compounds in order to understand dynamical behavior. Most of this family members exhibit a structural phase transition with temperature [14, 15]. A variety of models have been proposed to explain AC conduction mechanisms $[16,117]$. Since the complex impedance spectroscopy is a reliable method that can be used to study conduction processes $[18,19]$, its measurements are reported in this paper. The AC conductivity and dielectric relaxation behavior of $\mathrm{NH}_{3}\left(\mathrm{C}_{6} \mathrm{H}_{4}\right)_{2} \mathrm{NH}_{3} \mathrm{HgCl}_{4}$ single crystal have also been studied as a function of temperature and frequency.

\section{EXPERIMENTAL}

\subsection{Materials and measurements}

All reagents were purchased and used without further purification. Concerning the differential scanning calorimetry (DSC) measurements, they were carried out on heating sample $(6 \mathrm{mg})$ from $25-200^{\circ} \mathrm{C}$ on a Pyris 1 instrument at a heating rate of $5^{\circ} \mathrm{C} / \mathrm{min}$. As for the thermogravimetric analysis, it was obtained with a TGA 92 SETARAM analyzer. The powdered sample $(10 \mathrm{mg})$ was heated from room temperature up to $300^{\circ} \mathrm{C}$ at a rate of $5^{\circ} \mathrm{C} / \mathrm{min}$.

The electrical measurements were performed using a two-electrode configuration on a polycristalline sample. The used pellets, whose discs were coated with $\mathrm{Ag}$ paste to ensure good electrical contact, were $8 \mathrm{~mm}$ in diameter and $1.2 \mathrm{~mm}$ in thickness. After the $\mathrm{Ag}$ coating and before measurements, the samples were first heated at $100{ }^{\circ} \mathrm{C}$ for 12 hours under vacuum. Electrical impedances were measured in the frequency range of $209 \mathrm{~Hz}-5 \mathrm{MHz}$ with a TEGAM 3550 ALF automatic bridge monitored by a microcomputer. Measurements were conducted from $358-413 \mathrm{~K}$.

\subsection{Chemical preparation}

The synthesis of $\mathrm{NH}_{3}\left(\mathrm{C}_{6} \mathrm{H}_{4}\right)_{2} \mathrm{NH}_{3} \mathrm{HgCl}_{4}$ was performed from precursors benzidine $(98 \%)$, the transition metal halide $\mathrm{HgCl}_{2}(99.99 \%)$ and $\mathrm{HCl}(36 \%) .0 .27 \mathrm{~g}(1.5 \mathrm{mmol})$ of 1,4-biphenylenediamine, dissolved in $10 \mathrm{ml}$ distilled water/ethanol $(1: 1 \mathrm{v} / \mathrm{v})$, and $0.41 \mathrm{~g}(1.5 \mathrm{mmol})$ of $\mathrm{HgCl}_{2}$ dissolved in dilute hydrochloric acid were slowly combined. The obtained solution was kept at room temperature. After several days, plate colorless crystals appeared.

\section{RESULTS AND DISCUSSIONS}

\subsection{Structure description}

The title compound is crystallized with $\mathrm{C} 2 / \mathrm{c}$ space group and the parameters are given as: $\mathrm{a}=14.3774(7), \mathrm{b}=$ $7.3472(4), c=28.5854(17), \alpha=96.589(3)^{\circ}$, with $Z=2$ and $R_{1}=0.049$ [20]. The crystal structure of the material under investigation consists of alternating layers of organic and inorganic sheets stacked along [001] direction, Fig. 1. Organic and inorganic layers are interconnected through five $\mathrm{N}-\mathrm{H} \cdots \mathrm{Cl}$ hydrogen bonds and one bifurcated hydrogen bonding. The mercury $(\mathrm{Hg})$ atom is tetrahedrally coordinated by chlorine atoms, with $\mathrm{Hg}-\mathrm{Cl}$ distances ranging from 2.349(2) to 2.728(2) $\AA$ and $\mathrm{Cl}-\mathrm{Hg}-\mathrm{Cl}$ angles varying from $96.11(7)$ to $145.96(8)^{\circ}$. Those values show a high distortion of the $\mathrm{HgCl}_{4}{ }^{2-}$ tetrahedron, which are similar results to those known for some tetrachloromercurate anions [21, 22]. 


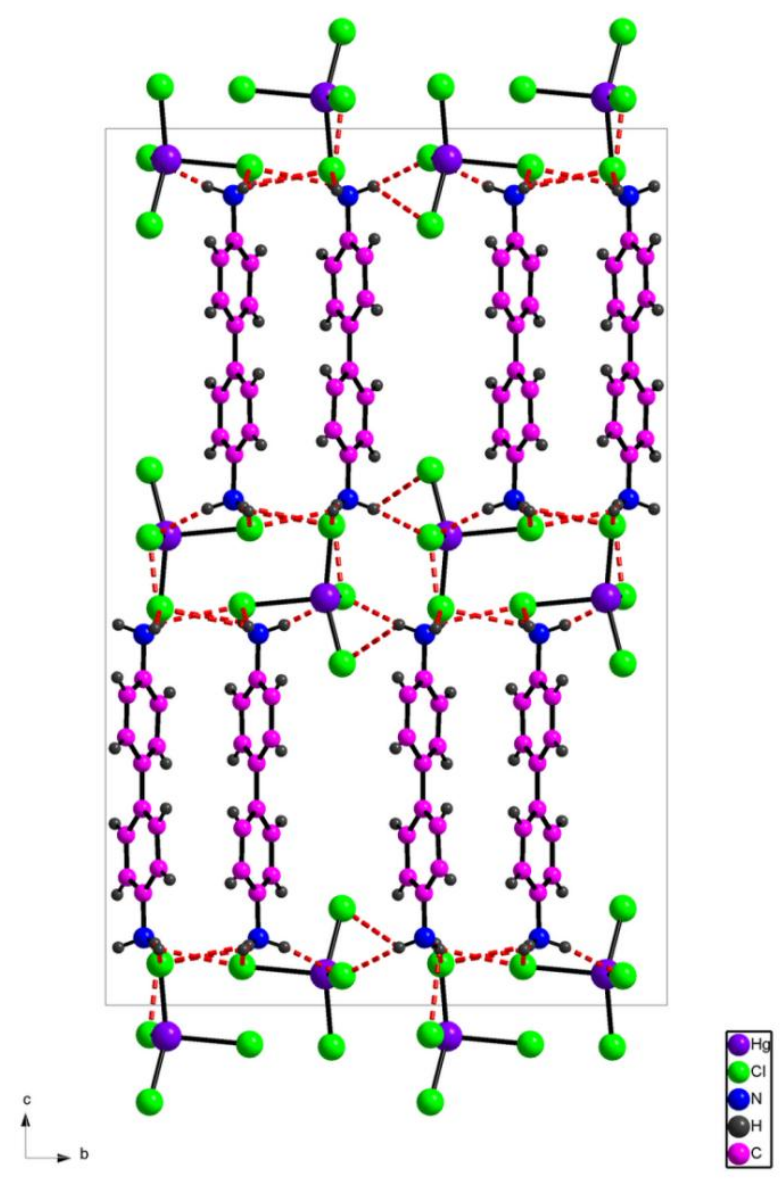

Fig 1: View down the a axis of the structure of the $\mathrm{NH}_{3}\left(\mathrm{C}_{6} \mathrm{H}_{4}\right)_{2} \mathrm{NH}_{3} \mathrm{HgCl}_{4}$ compound, showing alternating organic inorganic layers

\subsection{Thermal analysis}

The results of DSC measurements are presented in Fig. 2. One endothermic signal event with an onset temperature of $391 \mathrm{~K}$ is observed, which corresponds to the phase transition. Fig. 3 presents the results of the thermogravimetric analysis of $\mathrm{NH}_{3}\left(\mathrm{C}_{6} \mathrm{H}_{4}\right)_{2} \mathrm{NH}_{3} \mathrm{HgCl}_{4}$. No weight loss was detected between room temperature and $473 \mathrm{~K}$, which confirms that the observed peak is a transition.

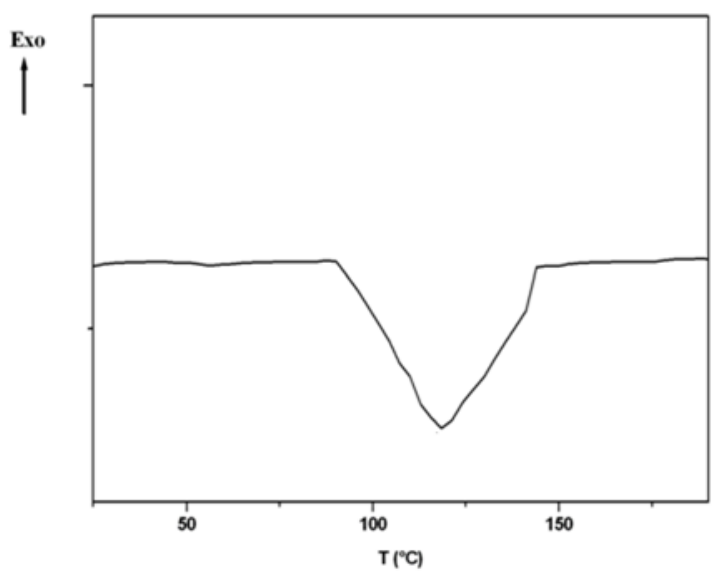

Fig 2: Differential canning calorimetry of the $\mathrm{NH}_{3}\left(\mathrm{C}_{6} \mathrm{H}_{4}\right)_{2} \mathrm{NH}_{3} \mathrm{HgCl}_{4}$ compound 


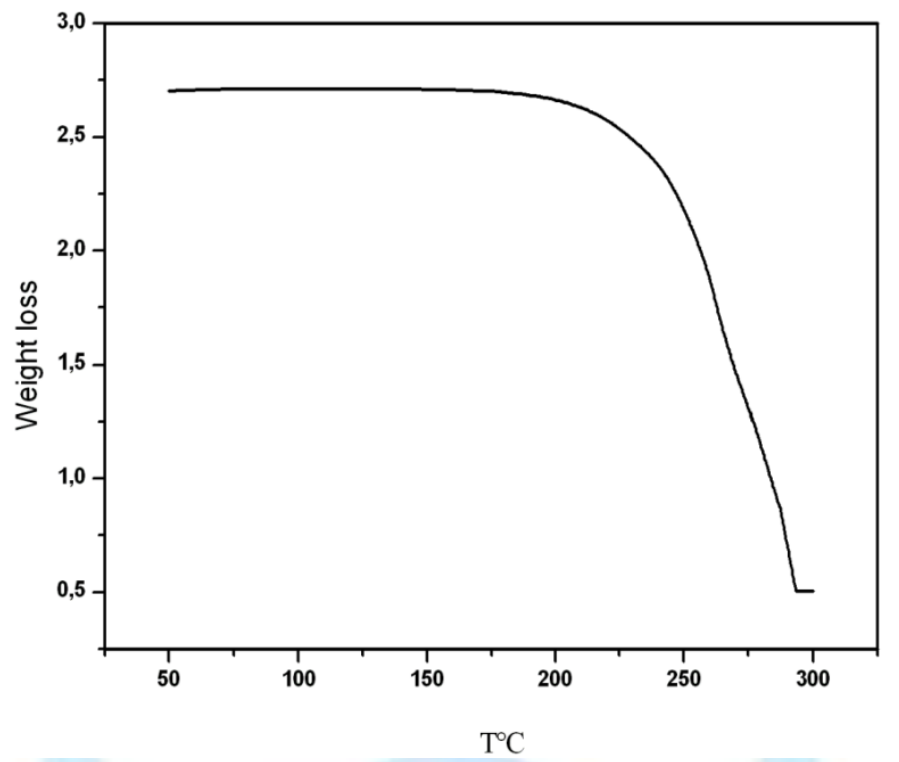

Fig 3: Thermogravimetric analysis of the $\mathrm{NH}_{3}\left(\mathrm{C}_{6} \mathrm{H}_{4}\right)_{2} \mathrm{NH}_{3} \mathrm{HgCl}_{4}$ compound

\subsection{Impedance analysis}

It is worthy to note that complex impedance formalism is one of the significant experimental techniques to provide information about the relaxation process analyzing the dynamics of the ionic mobility in solids. It also allows the determination of the conductivity of materials and other characteristics such as activation energy.

Fig. 4 (a) and (b) show the plot of (Z') versus Z' taken over the frequency range from $209 \mathrm{~Hz}$ to $5 \mathrm{MHz}$ at different temperatures ( $358 \mathrm{~K} \leq \mathrm{T} \leq 413 \mathrm{~K})$.

The appearance of two semicircles in the Cole-Cole plots at high temperatures indicates that there are two relaxation mechanisms that may be due to grain and grain boundary [23].

The equivalent circuit of the compound is well described by a combination series of two parallel (R//CPE) circuits that are connected in series with each other.

The impedance of CPE is: $Z_{\mathrm{CPE}}=\left[Q_{1}(j \omega)^{\alpha}\right]^{-1}$

where $Q$ indicates the value of the capacitance of the CPE element and $\alpha$ the degree of deviation with respect to the value of the pure capacitor.

The grain boundary effect can be assigned to the low frequency semicircular arc, whereas the grain (bulk) of the material can be assigned to the higher frequency semicircular arc. The grain resistance $\left(R_{g}\right)$ and grain boundary resistance $\left(R_{g b}\right)$ relative to the experimental temperature are the intercept of the semicircular arcs on the real axis [24]. It is to be noted that $\left(R_{g}\right)$ and $\left(R_{g b}\right)$ decrease with the rise in temperature. The impedance of the equivalent circuit (Fig. 5$)$ in terms of grain and grain boundary resistance [25] where $C_{g}$ and $C_{g b}$ refers to grain and grain boundary capacitance, respectively.

The variation of real ( $\left.Z^{\prime}\right)$ and imaginary ( $\left.Z^{\prime \prime}\right)$ parts of the impedance with frequency at various temperatures is shown in Fig. 6 and 7. Indeed, the magnitude of $Z$ " decreases with the increase in temperature and the peak frequency shifts to the higher values, which induces a thermally activated nature of the relaxation times. As for the broad nature of the peaks, it indicates multiple relaxation times in the system. The relaxation process may be due to the presence of immobile species at low temperature and defects/vacancies at higher temperature.

It is observed that the good conformity of the calculated lines with the experimental data indicates that the suggested equivalent circuit describes the crystal-electrolyte interface reasonably well.

The conductivity increases with the increase in temperature. In fact, above $388 \mathrm{~K}$ a little tail at lower frequencies can be observed. Besides, the conductivity $\sigma$ is obtained from $Z_{0}$ by means of the relation: $\sigma=e / Z_{0} S$, where e/S represents the geometrical ratio sample. The temperature dependence of the conductivity $(\operatorname{In}(\sigma T)$ versus $1000 / T)$ in the studied temperature range is given in Fig. 8. Moreover, an Arrhenius type behavior, $\sigma T=A \exp \left(-E_{0} / k_{B} T\right)$, is shown [26] and a change in the slope of the linear curve with a discontinuity in the temperature range of $388-391 \mathrm{~K}$ is observed. Furthermore, two regions of conductivity indicated as I and II are observed. The values of activation energies determined from Fig. 8 in regions I and II are 2.46 and $0.33 \mathrm{eV}$, respectively. Consequently, the conduction is explained by the thermally activated mechanism [27]. 

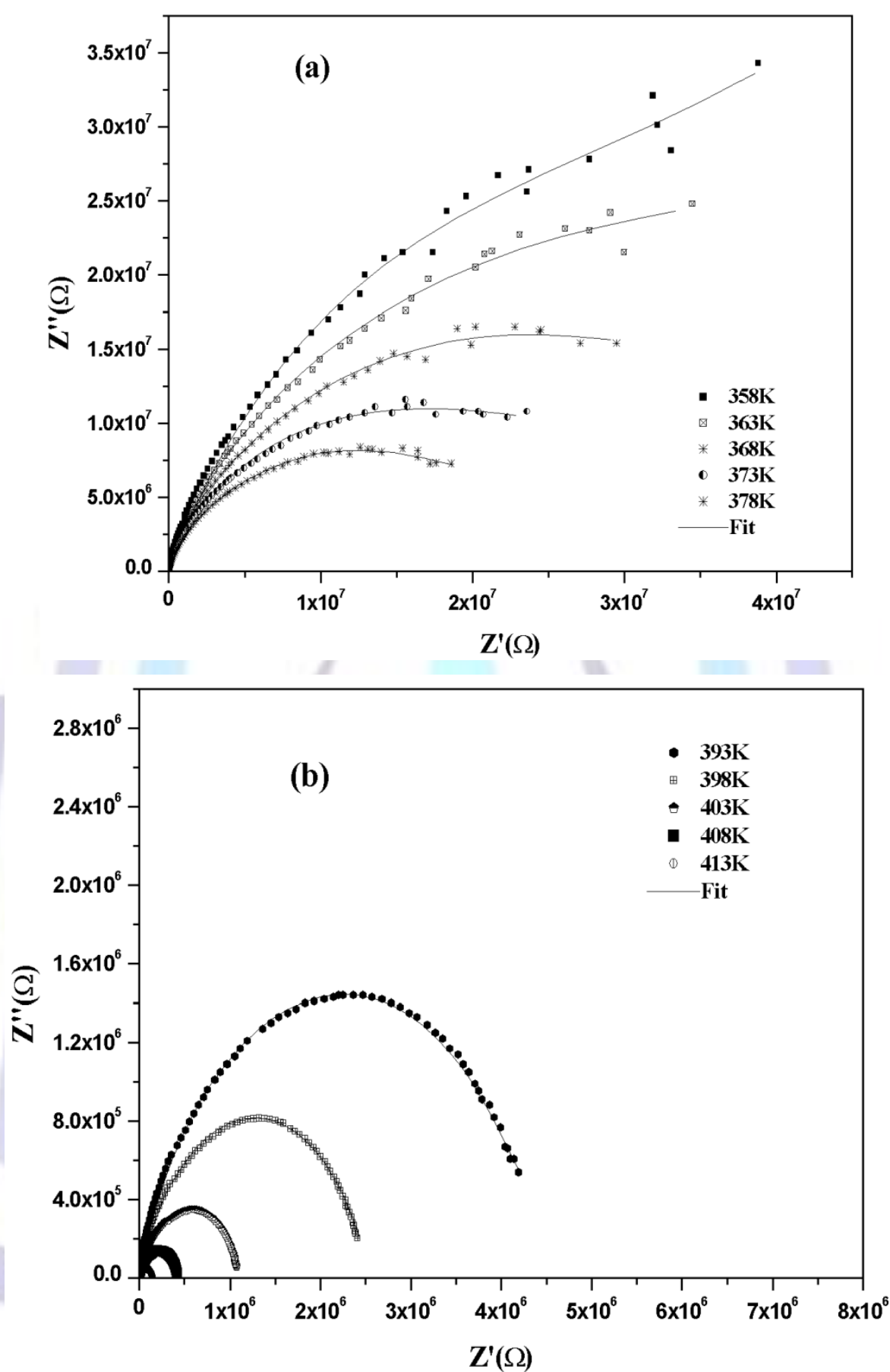

Fig 4: Complex impedance spectra at different temperatures (dashed lines); the solid line is a fit of the experimental data corresponding to the electrical equivalent circuit

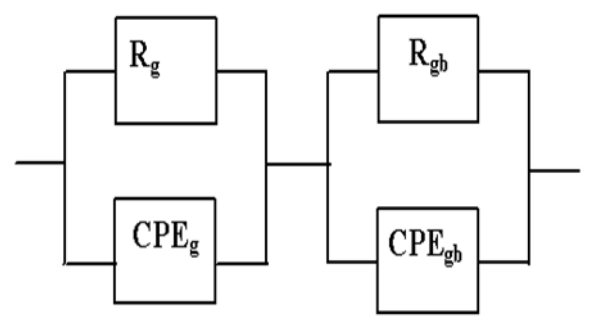

Fig 5: Equivalent circuit model of the $\mathrm{NH}_{3}\left(\mathrm{C}_{6} \mathrm{H}_{4}\right)_{2} \mathrm{NH}_{3} \mathrm{HgCl}_{4}$ compound 


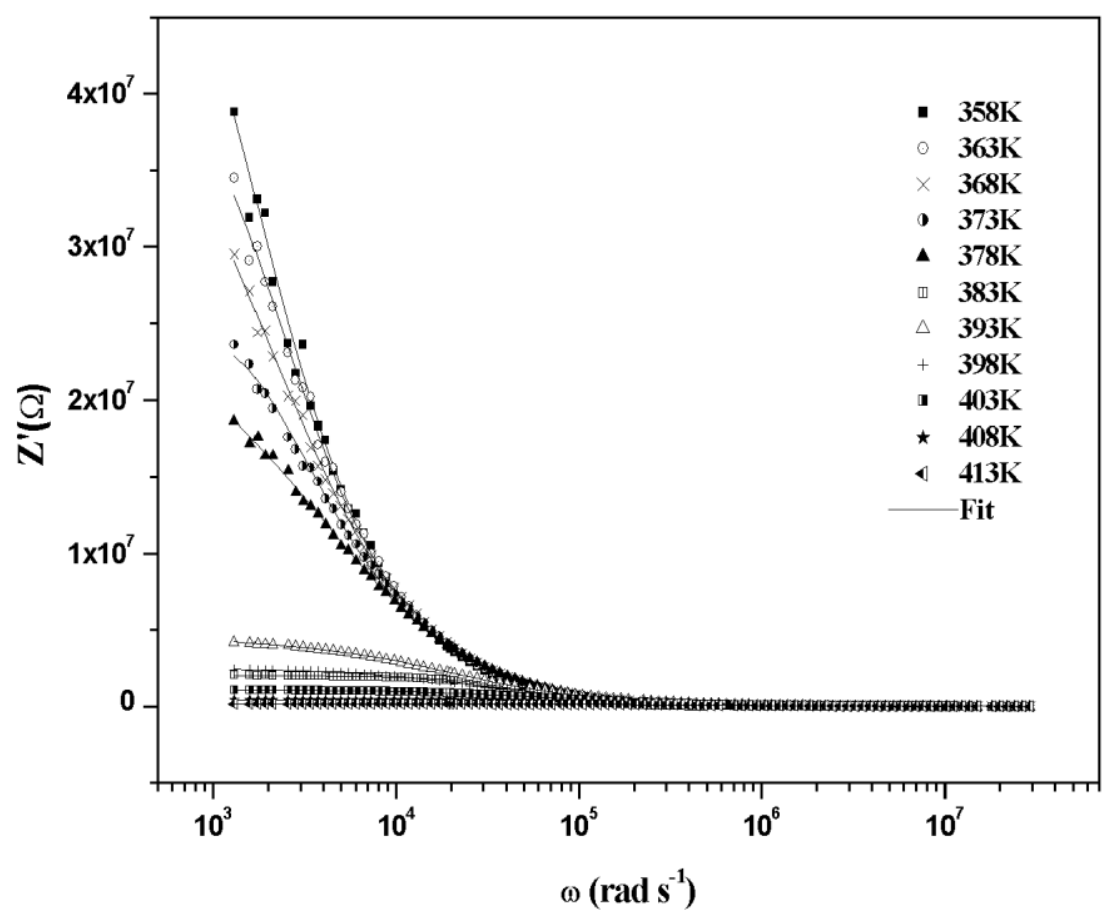

Fig 6: Variation of $Z$ with angular frequency at different temperatures of the $\mathrm{NH}_{3}\left(\mathrm{C}_{6} \mathrm{H}_{4}\right)_{2} \mathrm{NH}_{3} \mathrm{HgCl}_{4}$ compound

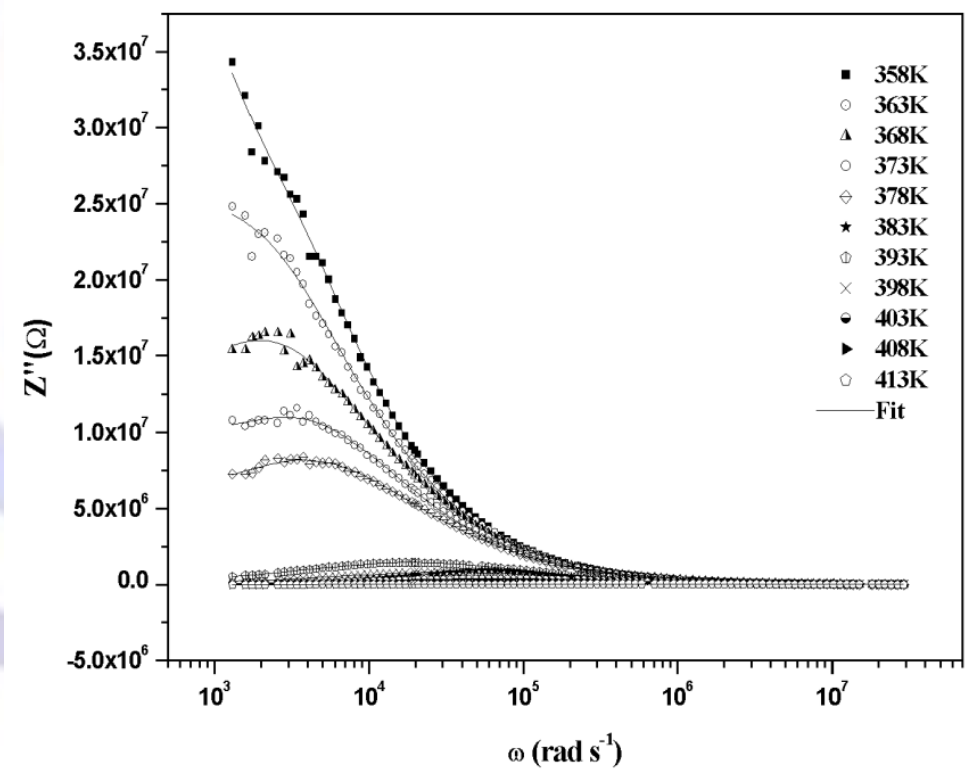

Fig 7: Variation of Z"' with angular frequency at different temperatures of the $\mathrm{NH}_{3}\left(\mathrm{C}_{6} \mathrm{H}_{4}\right)_{2} \mathrm{NH}_{3} \mathrm{HgCl}_{4}$ compound 


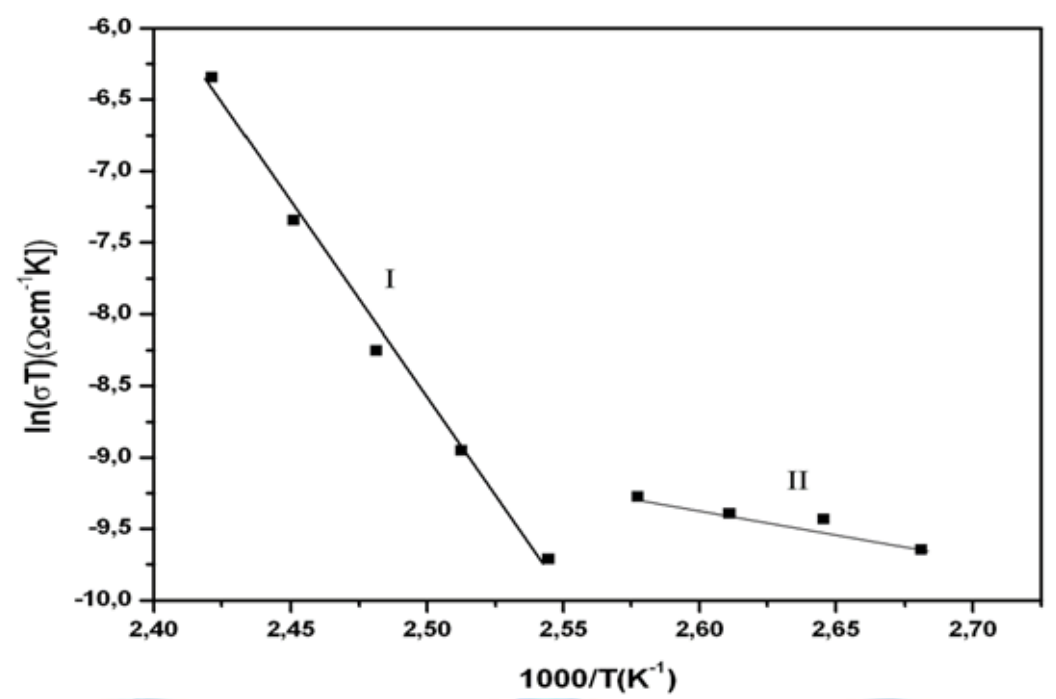

Fig 8: Temperature dependence of conductivity relaxation frequency and conductivity obtained from complex permittivity

\subsection{Modulus analysis}

The complex modulus formalism has been used in the analysis of the electrical properties because it gives the main response of the bulk of the polycrystalline. Besides, it is particularly suitable to extract phenomena such as electrode polarization and conductivity relaxation times. The complex electric modulus can be represented by the following equation [28-31]:

$$
\begin{aligned}
& M^{*}=1 / \varepsilon^{*}=M^{\prime}+i M^{\prime \prime} \\
& M^{*}=M_{\infty}\left[1-\int_{0}^{\infty} e^{-j w t}\left(-\frac{d \varphi(t)}{d t}\right) d t\right]
\end{aligned}
$$

where $M{ }^{\prime \prime}{ }_{\infty}=1 / \varepsilon_{\infty}$ is the inverse of the high frequency dielectric constant $\varepsilon$ and the stretched exponential function is defined by the empirical Kohlrausch-Williams-Watts (K.W.W.) function [32]:

$$
\varphi(t)=\exp \left(-\left(\frac{t}{\tau_{K W W}}\right)^{\beta}\right)
$$

where $\tau k w w$ is the characteristic relaxation time and $\beta$ is the well-known Kohlrausch parameter.

At lower frequencies, $M^{\prime}$ tends to be very small, confirming that the electrode effects make a negligible contribution and hence may be ignored when the data are analyzed in modulus representation. It is also characterized by a very low value $(\sim 0)$ of $\mathrm{M}^{\prime}$ in the low-frequency region. A continuous dispersion with the increase in frequency has a tendency to saturate at a maximum asymptotic value designated by $\mathrm{M}_{\infty}$, in the high-frequency region for all temperatures. This is due to the relaxation processes that are spread over a range of frequencies (Fig. 9).

Best fits for M" at different temperatures of the polycrystalline are shown in Fig. 10. Indeed, M" reaches a constant value $M_{\infty}\left(M_{\infty}=1 / \varepsilon_{\infty}\right)$ at high frequencies for all temperature, which is due to the relaxation processes that are spread over a range of frequencies [33]. The peaks in the M" plots shift toward higher frequencies and their height increases with the rise in temperature. This reveals that when the frequency is high, the temperature for which the measuring frequency is equal to $f_{p}$ is also high, while the peaks are broader and more asymmetric on both sides of the maxima than predicted by ideal Debye behaviour. From this graph and in the first curves, there are two areas that are very close, while in the second, the curves are far apart. This confirms the existence of two conduction areas. Such results are consistent with those obtained from the conductivity. The asymmetric M" plot is suggestive of the stretched exponential character of the relaxation times of the material. 


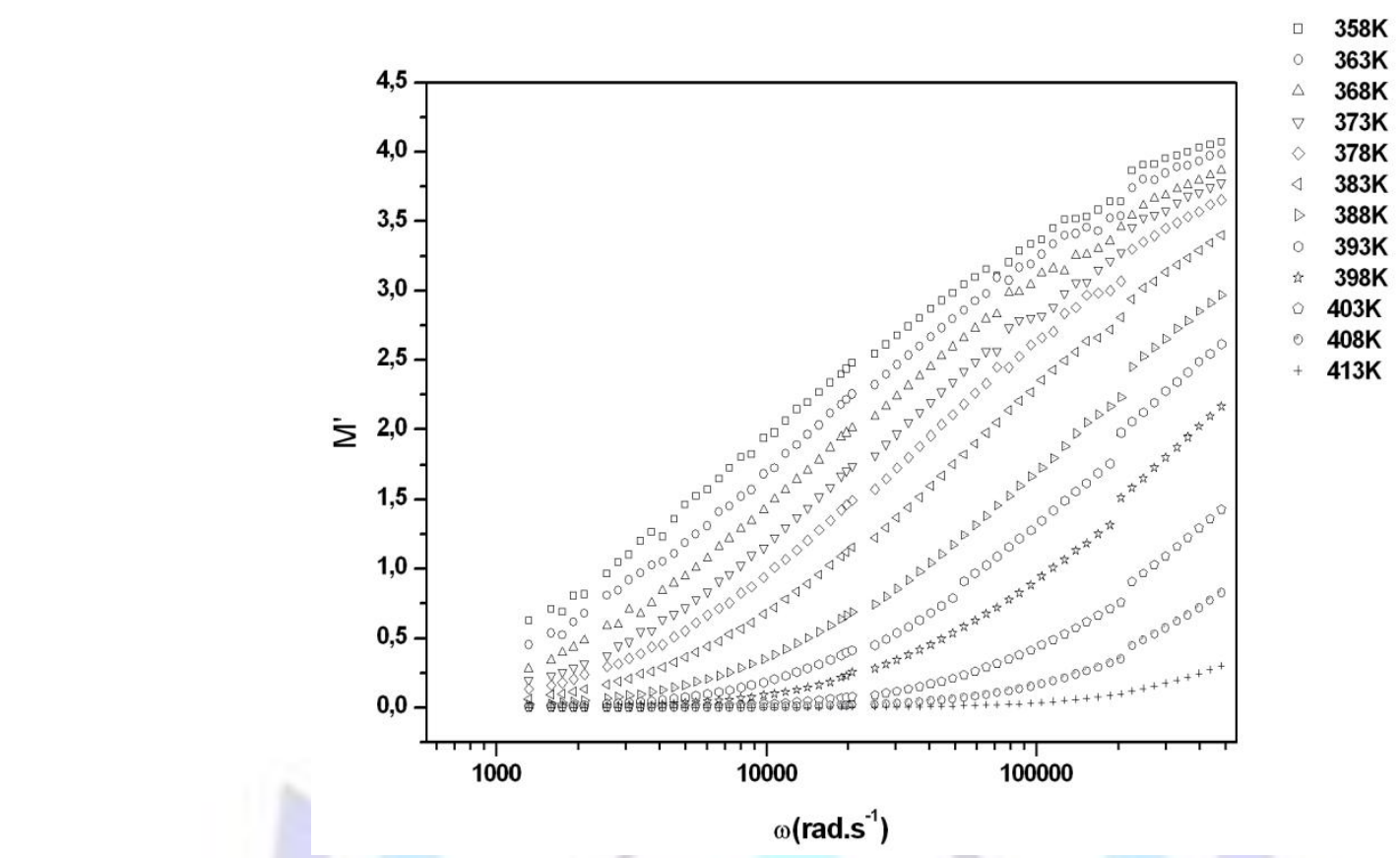

Fig 9: Frequency dependencies of M' at different temperature
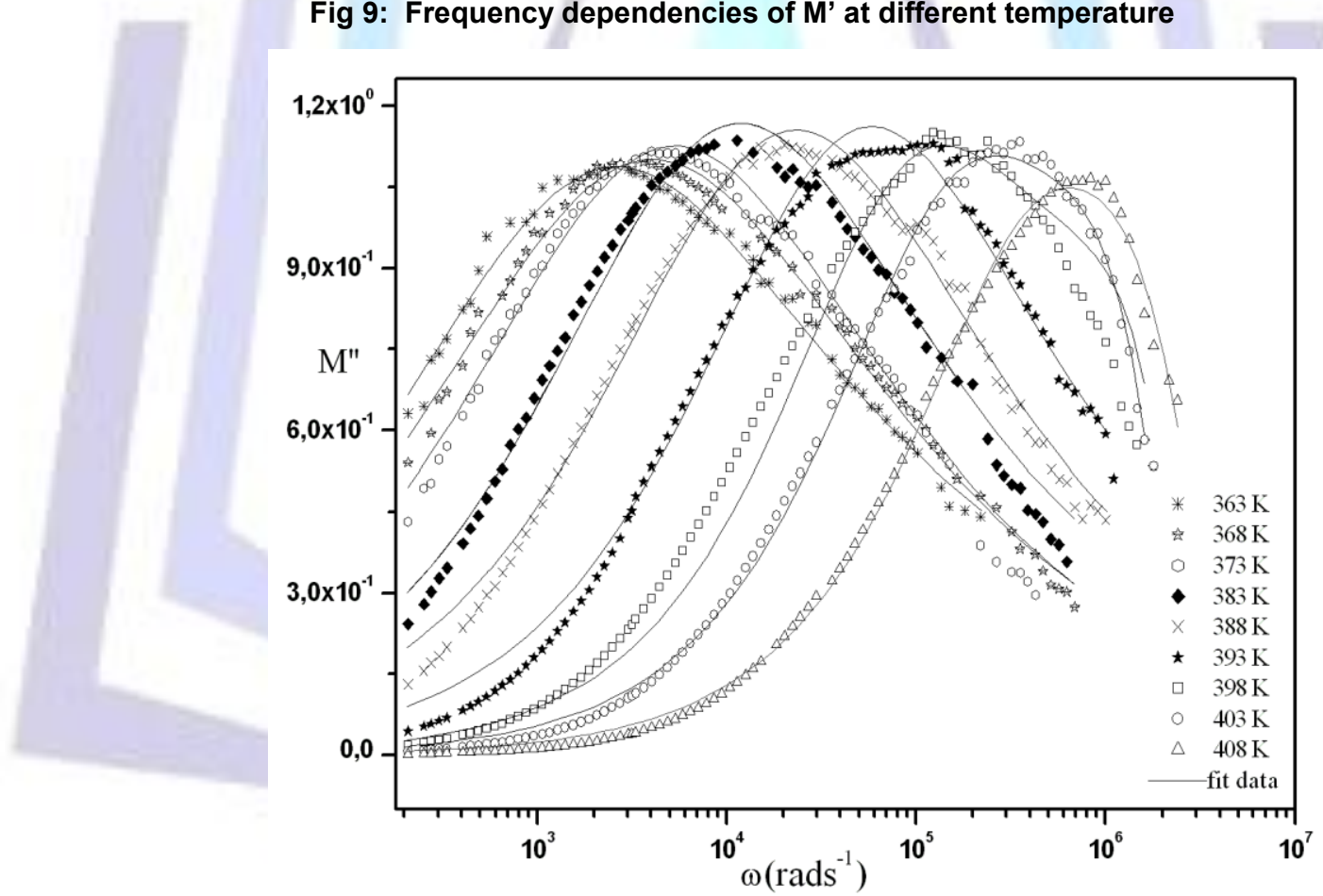

Fig 10: Frequency dependencies of $\mathbf{M}$ " at different temperatures. Solid curves are the best fits to the modulus formalism

\subsection{Conductivity analysis}

The Ac conductivity is generally expressed as [34]:

$$
\begin{aligned}
\sigma_{\text {Total }} & =\sigma_{\mathrm{dc}}+\sigma_{\mathrm{ac}} \\
& =\sigma_{0}+A \omega^{\mathrm{s}}
\end{aligned}
$$

where $\sigma_{\mathrm{dc}}\left(=\sigma_{0}\right)$ is the frequency independent component, $A$ is a temperature-dependent constant, $s$ is the frequency exponent and $\sigma_{\mathrm{ac}}\left(=\mathrm{A} \omega^{\mathrm{s}}\right)$ represents the dissipative contribution to the total conductivity, which depends both on the temperature and composition of the single crystal [35-37]. Equation (5) is referred to as the universal dynamic pattern of ac electrical behavior of conducting solids as proposed by Jonscher [38]. The variation in conductivity as a function of the 
frequency of the $\mathrm{NH}_{3}\left(\mathrm{C}_{6} \mathrm{H}_{4}\right)_{2} \mathrm{NH}_{3} \mathrm{HgCl}_{4}$ compound at various temperatures is reported in Fig. 11 . This representation shows the increase in conductivity with frequency. There are two parts of these curves, in the first of which there is a very sharp drop in conductivity at high frequencies around $105 \mathrm{~Hz}$ and in the second one corresponding to the lower frequency to $105 \mathrm{~Hz}$, the conductivity increases more and more to $10^{-7}(\Omega . \mathrm{cm})^{-1}$.

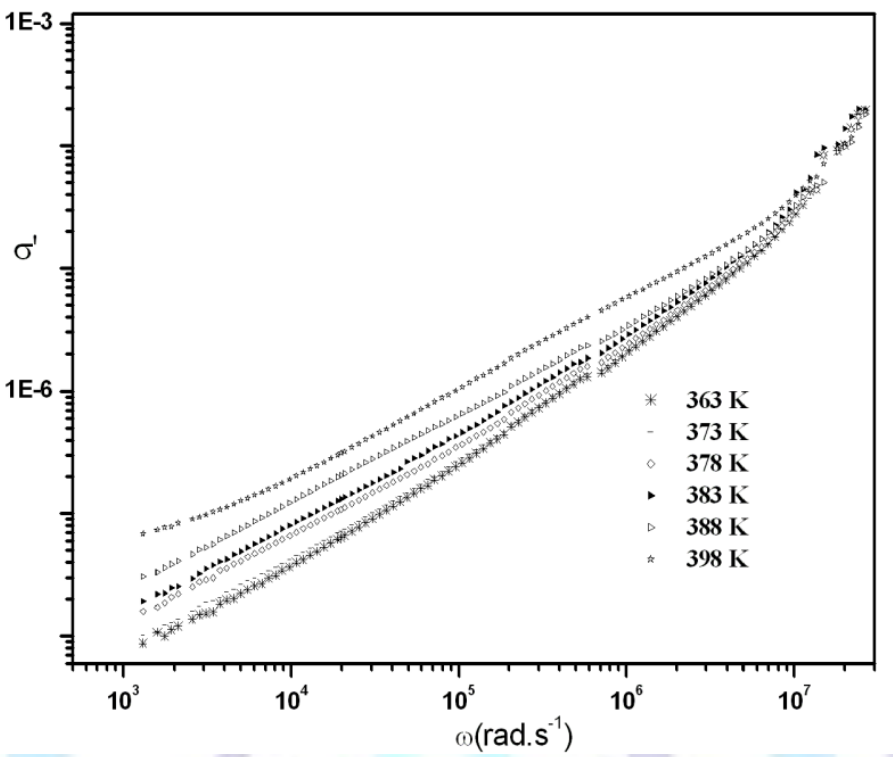

Fig 11: Frequency dependencies of the real part of Ac complex conductivity at several temperatures

Fig. 12 shows the frequency dependence of the dielectric constant $\varepsilon$ " $(\omega)$ at fixed temperatures.

The measured impedance is used to calculate the imaginary ( $\left.\varepsilon^{\prime \prime}\right)$ parts of the complex dielectric permittivity as [39] Eq (6):

$$
\varepsilon^{\prime \prime}(\omega)=\frac{\left(\varepsilon_{s}-\varepsilon_{\infty}\right)\left(\frac{\omega}{\omega_{1}}\right)^{1-\alpha} \sin \left(\frac{(1-\alpha) \pi}{2}\right)}{1+2\left(\frac{\omega}{\omega_{1}}\right)^{1-\alpha} \cos \left(\frac{(1-\alpha) \pi}{2}\right)+\left(\frac{\omega}{\omega_{1}}\right)^{2(1-\alpha)}}+\frac{\sigma_{0}}{\varepsilon_{0} \omega}
$$

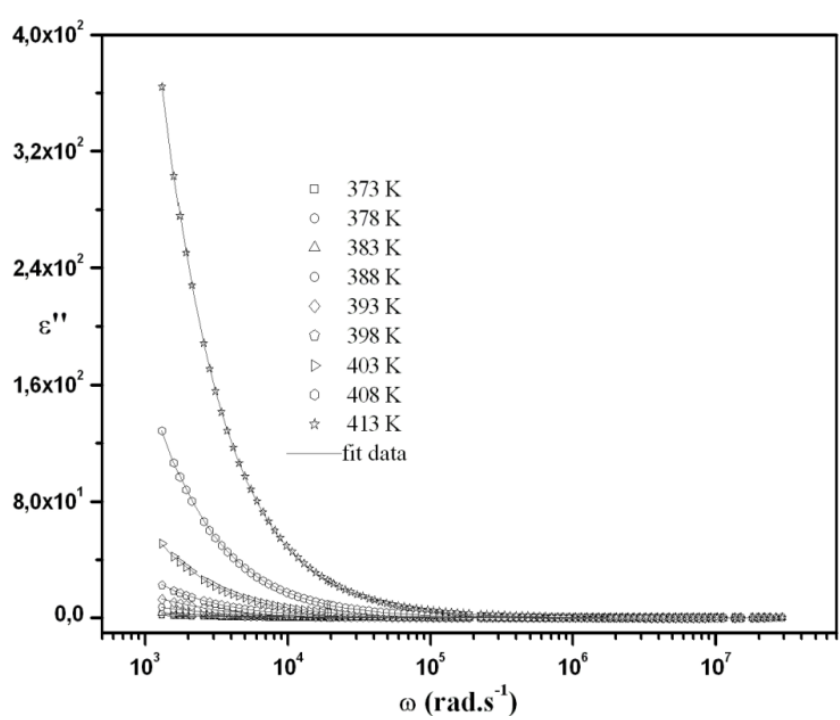

Fig 12: Frequency dependencies of the imaginary part of permittivity at several temperatures

where the parameter $\alpha$ represents the tilting angle $(\alpha \pi / 2)$ of the circular arc from the real axis in the complex permittivity plane, $\omega$ is the frequency, $\sigma_{0}$ the specific conductivity and $\varepsilon_{0}$ the dielectric permittivity of vacuum [40]. As the temperature 
increases, the dielectric constants at low frequency show a dispersive behavior [26]. Actually in the low frequency region of the $\varepsilon$ " spectrum a clear tail connected to the conductivity was observed. Best fits using the function (6) give a suitable fitting of the curves resulting from the experimental data.

\section{CONCLUSION}

The compound $\mathrm{NH}_{3}\left(\mathrm{C}_{6} \mathrm{H}_{4}\right)_{2} \mathrm{NH}_{3} \mathrm{HgCl}_{4}$ was synthesized by slow evaporation at room temperature. DSC study indicates the presence of a phase transition at $391 \mathrm{~K}$. The analysis of the frequency dispersion of the real and imaginary components of the complex impedance has allowed the determination of an equivalent electrical circuit for an electrochemical cell with $\mathrm{NH}_{3}\left(\mathrm{C}_{6} \mathrm{H}_{4}\right)_{2} \mathrm{NH}_{3} \mathrm{HgCl}_{4}$. Besides, the $\mathrm{AC}$ conductivity, described by Jonscher's behaviour, and electric behavior of $\mathrm{NH}_{3}\left(\mathrm{C}_{6} \mathrm{H}_{4}\right)_{2} \mathrm{NH}_{3} \mathrm{HgCl}_{4}$ were studied as a function of temperature and frequency. Besides, the frequency-dependent conductivity of the material at different temperatures was analyzed using the Jonscher's power law, and the temperature-independent frequency exponent term was then evaluated. The analysis of the temperature variation of the $M$ ' peak has indicated that the observed relaxation process is thermally activated.

\section{REFERENCES}

[1] M. Góśniowska, Z. Ciunik, G. Bator, R. Jakubas, J. Mol. Struct. 511, 345 (1999)

[2] M. Nakayama, M. Fukuda, Solid State lonics 178, 1095 (2007)

[3] M. Fujita, Y. J. Kwon, S. Washizu, K. Ogura, J. Am. Chem. Soc. 116 ,1151 (1994)

[4] G.B. Gardner, D. Venkataraman, J.S. Moore, S. Lees, Nature 374, 792 (1995)

[5] S. W. Keller, Angew. Chem, Int. Ed. Engl. 36, 247 (1997)

[6] Z. Xu, S. White, L. K. Thompson, D. O. Miller, M. Ohba, H. Okawa, C. Wilson, J. A. K. Howard, J. Chem. Soc. Dalton Trans. 1751 (2000)

[7] M. Eddaoudi, D. B. Moler, H. Li, B. Chen, T. M. Reinecke, M. O’Keeffe , O.M. Yaghi, Acc. Chem. Res. 34, 319 (2001)

[8] D.B. Mitzi, Chem. Mater. 13, 3283 (2001)

[9] Z. Xu, D. B. Mitzi, Inorg. Chem. 42, 6589 (2003)

[10] Z. Xu, D. B. Mitzi, C. D. Dimitrakopoulos, K. R. Maxcy, Inorg. Chem. 42, 2031 (2003)

[11] K. Ma, J. Xu, P. Zhang, Y. Wang, J. Wang, Y. Fan, T. Song, Solid State Sci. 8, 1473 (2006)

[12] R.D. Willett, C.J. Gomez-Garcia, B. Twamley, Polyhedron 24, 2293 (2005)

[13] A. Jarboui, B. Louati, F. Hlel, Kamel Guidara, J. Alloys Compd. 503, 340 (2010)

[14] J. Diaz-Hernández, G. Aguirre-Zamalloa, A. López-Echarri, I. Ruiz-Larrea, T. Breczewski, M. J. Tello, J. Phys. Condens.Matter 9, 3399 (1997)

[15] A. Ben. Rhaiem, N. Zouari, K. Guidara, M. Gargouri, A. Daoud, J. Alloys. Compd. 387,1 (2005)

[16] M. Pollak, T. H. Geballe, J. Phys. Rev. 122, 1742 (1961)

[17] S. R. Elliott, N. F. Mott, J. Adv. Phys. 18, 41(1969)

[18] S. Sen, R. N. P. Chaudhary, Mater. Chem. Phys. 87, 256 (2004)

[19] J. Suchanicz, Mater. Sci. Eng. B. 55, 114 (1998)

[20] M.Belhouchet, W. Wamani, T. Mhiri, IOP Conf. Series: Materials Science and Engineering 13,12039 (2010)

[21] M. Amami, R. Zouari, A. Ben Salah, H. Burzlaff, Acta. Cryst. E58, m357 (2002)

[22] R. Spengler, R. Zouari, A. Ben Salah, H. Zemmermann, H. Burzlaff, Acta. Cryst. C54, 1628 (1998)

[23] J. R. Macdonald, Impedance Spectroscopy Wiley NY 1987 Delhi (2004)

[24] K.S. Rao, D. M. Prasad, P. M. Krishna, B. Tilak, K. Ch. Varadarajulu, Mater. Sci. Eng. B 133, 141 (2006)

[25] R. P. Tandon, J. Korean Phys Soc. 32, 327 (1998)

[26] K.S. Rao, P. M. Krishna, D. M. Prasad, J.H. Lee, J. S. Kim, J. Alloys Compd. 464, 497 (2008)

[27] R. Ayouchi, D. Leien, F. Martin, M. Gabas, E. Dalchiele, J. R. Ramos-Barrodo, Thin Solid Films. 68, 426 (2003)

[28] P. B. Macedo, C. T. Mognihan, R. Bose, Phys Chem Glasses. 13, 171 (1972) 
[29] M. Ganguli, M. Harish Bhat, K. Rao, J Phys Chem Glasses. 40, 297 (1999)

[30] S. Lanfredi, P. S. Saia, R. Lebullenger, A. C. Hernandes, Solid State Ionics. 146, 329 (2002)

[31] S. Ghosh, A. Ghosh, Solid State lonics. 149, 67 (2002)

[32] G. Williams, D. C. Watts, Trans. Faraday Soc. 66, 80 (1970)

[33] F. S. Howell, Bose, P.B .Macedo, C. T. Moynihan, J. Phys. Chem. 78, 639 (1974)

[34] A. Mansingh, V. K Dhawan, J Phys C Solid State Phys. 16, 1675 (1983)

[35] H .El Mkami, B .Deroide, R. Backov, J .Vzanchetta, J .PhysChem Solids 61 (2000)

36. N. F. Mott, E. A. Davis, Electronic Processes in Non-crystalline Materials, seconded. Clarendon, Oxford 225 (1979)

[37] S. R. Elliott, Adv Phys .36, 135 (1987)

[38] A. K. Jonscher, Nature . 267, 673 (1977)

[39] J. Suchanicz, Mater Sci Eng B. 55, 114 (1998)

[40] K. S. Cole, R. H. Cole, J. Chem. Phys.9, 341 (1941)

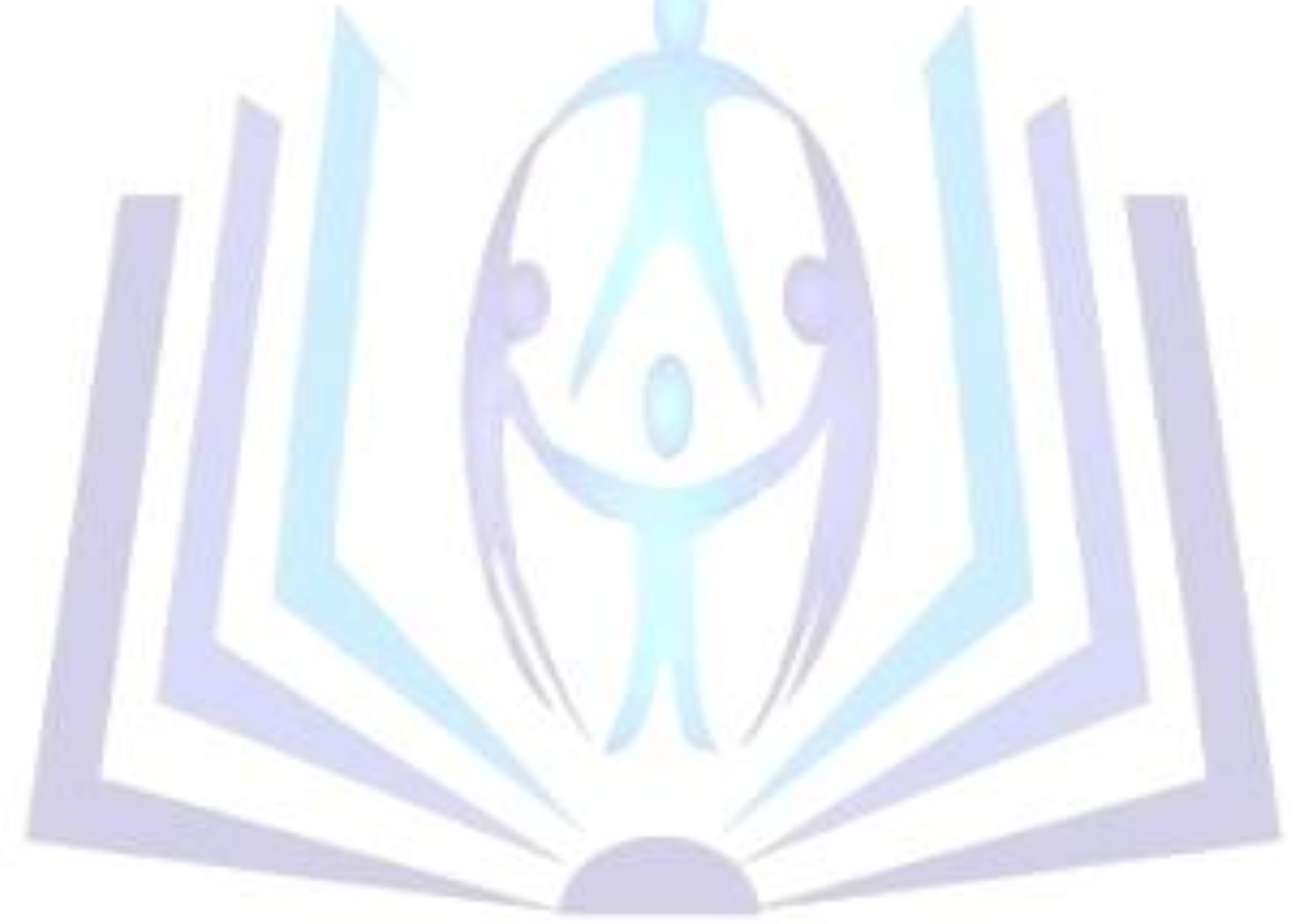

